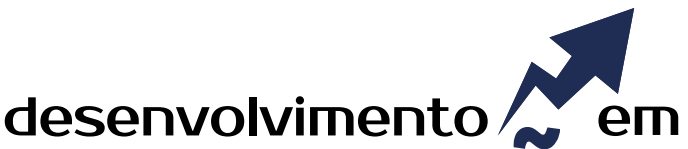 QUESTÃO
}

\section{Transparência na Gestão Pública Municipal Evidenciada nos Portais Eletrônicos dos Municípios do Conselho Regional de Desenvolvimento (Corede) das Missões/RS}

\author{
http://dx.doi.org/10.21527/2237-6453.2019.49.158-175 \\ Recebido em: 19/6/2018 \\ Aceito em: 23/5/2019
}

Monize Sâmara Visentini ${ }^{1}$, Micheli dos Santos²

\begin{abstract}
RESUMO
Neste estudo investigou-se a situação da transparência na gestão pública nos 25 municípios que integram o Corede Missões/ RS por meio dos seus portais eletrônicos, utilizando ranqueamento elaborado a partir da aplicação do índice de Transparência da Gestão Pública Municipal (ITGP-M), elaborado por Cruz (2010). Para a coleta dos dados, empregou-se um roteiro estruturado de observação a partir dos critérios de avaliação do ITGP-M, o qual quantifica a transparência municipal em até 143 pontos, divididos em seis categorias de informações. Os resultados indicam baixos níveis de transparência, demonstrando que nenhum dos 25 municípios investigados divulga completamente as informações acerca da gestão pública municipal. A média geral do índice de transparência (ITGP-M) foi de 53,68 pontos, posto que o município com menor pontuação obteve 35 pontos (Dezesseis de Novembro), enquanto o maior índice atingiu 76 pontos (São Luiz Gonzaga). Tal análise reflete que muitos dos portais dos municípios investigados configuram-se predominantemente como murais eletrônicos e não como espaços de construção da transparência. Grande parte desses portais possui características meramente informativas dos órgãos e departamentos da Prefeitura, tornando coadjuvante o cumprimento de grande parte dos requisitos legais para o atendimento das demandas informacionais da sociedade.
\end{abstract}

Palavras-chaves: Transparência. Municípios. Portais eletrônicos.

TRANSPARENCY IN THE MUNICIPAL PUBLIC MANAGEMENT EVIDENCED IN THE MUNICIPALITY HOMEPAGES OF CONSELHO REGIONAL DE DESENVOLVIMENTO (COREDE) OF MISSÕES/RS

\section{ABSTRACT}

This study investigated the situation of public management transparency in the 25 municipalities that integrate Corede Missões/RS, through its websites, using rankings developed from the application of the Transparency Index Municipal Public Management (ITGP-M), elaborated by Cruz (2010). For the data collection, a structured observation protocol was used, based on the evaluation criteria of the ITGP-M, which quantifies municipal transparency in up to 143 points, divided into six categories of information. The results indicate low levels of transparency, demonstrating that none of the 25 municipalities investigated fully discloses information about municipal public management. The general average of the transparency index (ITGP-M) was 53.68 points, with the lowest score having 35 points (Dezesseis de Novembro), while the highest index reached 76 points (São Luiz Gonzaga). This analysis reflects that many of the investigated municipalities websites are predominantly configured as electronic murals and not as spaces for transparency construction. Most of these websites have merely informative characteristics of the municipal government organs and departments, making compliance with most of the legal requirements to meet the informational demands of society.

Keywords: Transparency. Municipalities. Homepage.

\footnotetext{
${ }^{1}$ Doutora em Administração pela Universidade Federal do Rio Grande do Sul (UFRGS). Professora do Programa de Mestrado em Desenvolvimento e Políticas Públicas da Universidade Federal da Fronteira Sul (UFFS).monize.visentini@uffs.edu.br

${ }^{2}$ Mestre em Desenvolvimento e Políticas Públicas pela Universidade Federal da Fronteira Sul (UFFS). Assistente de Administração da Universidade Federal da Fronteira Sul (UFFS).micheli.santos@uffs.edu.br
} 
A temática transparência na gestão pública vem ganhando destaque nos últimos anos, pois os cidadãos têm despertado para uma visão mais crítica. Percebe-se uma maior abertura à participação na definição de políticas públicas, na cobrança por meIhoria nos serviços públicos e na atuação mais transparente e responsável por parte dos gestores.

Meijer (2013) discute a complexa dinâmica da transparência, esclarecendo que se trata de uma relação institucional, podendo ser analisada como um objeto/ator (administração pública) que pode ser monitorado, enquanto quem monitora a transparência assume o papel do segundo ator (cidadão que assume o papel de fiscalização). Entende-se, assim, que no desenrolar desta relação, na qual as atividades da gestão pública são expostas à conferência dos cidadãos, a corrupção é inibida e o processo de tomadas de decisão ocorre de forma democrática.

Nesse viés, ao analisar a gestão pública em âmbito municipal, permite-se tomar o espaço local como objeto de investigação, considerando que é na esfera local que a vida flui, que as pessoas interagem e preocupam-se com os problemas que querem ver resolvidos, sendo fundamental valorizar este espaço para viabilizar a prática da cidadania e facilitar a vida social e o desenvolvimento local (SANTOS; VISENTINI, 2018).

Castoldi e Santos (2013) destacam que a administração pública tem alcançado avanços rápidos e há a necessidade de coordenar os esforços na busca de conhecimentos e modelos de boas práticas de transparência, considerando que, apesar de relativamente novas, caracterizam-se como elementos indispensáveis no processo democrático e participativo da população para a consolidação das políticas regionalizadas, estreitando as relações entre os envolvidos. Os avanços tecnológicos, por intermédio da internet, oportunizaram aos governos atuarem de forma mais transparente, ao possibilitar a exposição de suas ações na grande rede para acesso universal do público, na qual, por meio das Tecnologias de Informação e Comunicação (TICS), são criados espaços de participação e fiscalização da gestão pública.

Esta discussão suporta a proposta deste artigo, que abrange o estudo da transparência na Gestão Pública Municipal por meio da mensuração do ITGP-M, índice desenvolvido por Cruz (2010). O modelo de investigação do ITGP-M tem sido usado em diversos estudos (ROSSONI, 2013; COSTA; TORRES, 2015; COSTA et al., 2015), mostrando-se eficiente por apresentar à sociedade uma fotografia da situação em que se encontra a transparência das informações divulgadas nos portais eletrônicos dos municípios, despertando interesse no meio acadêmico (CRUZ et al., 2012; COSTA et al., 2016; ROSSONI; BEIRUTH, 2016).

Cruz et al. (2012) evidenciaram índices de transparência considerados incompatíveis com o nível de desenvolvimento socioeconômico dos grandes municípios brasileiros, bem como associação entre as condições socioeconômicas dos municípios e os níveis de transparência na divulgação de informações acerca da gestão pública.

Costa et al. (2016) pesquisaram o nível de transparência nos portais das Prefeituras das capitais brasileiras, apurando que João Pessoa é a capital mais transparente, obtendo um índice de $52 \%$, ou seja, 75 pontos do total do ITGP-M, seguida de Belo Horizonte, que alcançou uma pontuação de 71 pontos dos 143 do ITGP-M, o equivalente a $50 \%$ do esperado. Na investigação houve destaque ainda para as capitais Florianópolis 
e Porto Alegre, que obtiveram pontuação de 68 e 69 pontos do ITGP-M, o equivalente a $48 \%$ do seu total. As demais capitais conquistaram, no máximo, 46\% do ITGP-M (Curitiba) e o mínimo de $17 \%$ (São Luís).

Já Rossoni e Beiruth (2016) classificaram quais Prefeituras do Estado do Espírito Santo são mais transparentes em relação à evidenciação de informações sobre a gestão pública municipal em seus portais eletrônicos, e quais características explicam o nível de transparência. Os resultados mostram que a prefeitura de Vitória é a mais transparente, registrando 85 pontos no ITGP-M. O estudo demonstrou que há associação positiva entre o nível de transparência e as variáveis população, índice Firjan de desenvolvimento municipal (IFDM) ${ }^{3}$ e a orientação político-partidária do prefeito.

Estes estudos preocuparam-se em avaliar municípios brasileiros de grande porte, e nenhum aborda os municípios localizados na área de abrangência do Conselho Regional de Desenvolvimento (Corede) das Missões-RS, objeto desta investigação. Este é um fator que corrobora o desenvolvimento desta pesquisa. Como arranjos institucionais, os Coredes equivalem a espaços públicos, nos quais é possível a prática da cidadania deliberativa, que traz aos municípios maior autonomia, rompendo o desenho tradicional das políticas públicas, ao mesmo tempo em que instituem políticas sociais, por intermédio de mecanismos de gestão democrática e participativa no âmbito local, em torno da discussão pública de questões específicas (ALLEBRANDT et al., 2011). O Corede Missões é constituído por 25 municípios, a maioria de pequeno porte e de perfil predominantemente rural, com taxa de urbanização de aproximadamente $70 \%$, conforme o último censo realizado pelo Instituto Brasileiro de Geografia e Estatística em 2010 (ATLAS..., 2018).

Diante da relevância do tema, o estudo objetiva investigar a situação da transparência na gestão pública nos municípios que integram o Corede Missões por meio dos portais eletrônicos, utilizando ranqueamento elaborado a partir da aplicação do ITGP-M.

Acredita-se que os resultados deste estudo tendem a indicar aos gestores públicos e cidadãos dos municípios investigados um panorama da atual situação da transparência na gestão pública municipal no âmbito do Corede Missões. Ao permitir aos cidadãos melhor conhecer o ambiente onde vivem e investem, espera-se que reflitam sobre a eficiência na gestão pública e a suficiência ou não das informações disponibilizadas, podendo intervir no processo de formulação de políticas públicas, auxiliando para o desenvolvimento regional. Além disso, estudos desta natureza têm o propósito de contribuir para que os gestores públicos analisem a forma como evidenciam a divulgação de informações em suas gestões, possibilitando orientá-los no desenvolvimento de políticas de disponibilização de informações claras e eficientes, o que pode auxiliar no estreitamento da relação governo cidadão.

\footnotetext{
3 O Índice Firjan de Desenvolvimento Municipal - IFDM - é um estudo do Sistema da Federação das Indústrias do Estado do Rio de Janeiro (Firjan) que acompanha, anualmente, o desenvolvimento socioeconômico de todos os mais de 5 mil municípios brasileiros em três áreas de atuação: Emprego \& renda, Educação e Saúde. Criado em 2008, ele é feito, exclusivamente, com base em estatísticas públicas oficiais, disponibilizadas pelos Ministérios do Trabalho, Educação e Saúde (Firjan, 2018).
} 


\section{PORTAIS ELETRÔNICOS GOVERNAMENTAIS E A TRANSPARÊNCIA}

Portal governamental é entendido como um ambiente único e integrado na internet, no qual o cidadão pode ter acesso a informações bem como solicitar serviços aos mais diversos agentes de governo, de maneira interativa e simples (BARBOSA, 2008). Diniz (2015) aduz que podem ser considerados como locais de comunicação entre os cidadãos e os governantes, privilegiando o estabelecimento de um ambiente coletivo de decisão e diálogo. De acordo com o mesmo autor, a propagação de portais governamentais tem sido propiciada, de um lado, pela cobrança cada vez maior dos cidadãos por maior transparência na gestão pública, pressionando os governos a abrirem seus sistemas e bancos de informação ao acesso universal; do outro lado, há a exigência legal, definida pela Lei de Acesso à Informação - LAI (BRASIL, 2011) -, que elegeu o canal obrigatório para a divulgação das iniciativas de transparência ativa, no § 20 do artigo 8 ㅇ, esclarecendo que, para cumprimento do disposto no caput, os órgãos e entidades públicas deverão utilizar todos os meios e instrumentos legítimos de que dispuserem, sendo obrigatória a divulgação em sítios oficiais da internet.

A principal vantagem dos portais governamentais é a capacidade de facilitar o exercício da cidadania, além de possibilitar o acesso a serviços públicos de forma on-line, diminuindo os atendimentos presenciais e aumentando o número de usuários atendidos em determinado espaço temporal (JAMBEIRO; SOBREIRA; MACAMBIRA, 2012). Cabe ao governo encontrar um meio de chegar ao cidadão, a fim de apresentar a ele esclarecimentos sobre como os recursos públicos estão sendo geridos em prol do bem comum, considerando que esta deve ser a finalidade de qualquer gestão pública (ALVES, 2011).

Assim, entende-se que, de acordo com a forma e os objetivos da criação dos portais eletrônicos, estes podem contribuir significativamente na construção da accountability, ${ }^{4}$ mesmo que se corra o risco de os mesmos servirem apenas como mural eletrônico, sem que haja prestação de contas, transparência e participação dos cidadãos (RAUPP; PINHO, 2012). O portal pode assumir a configuração de sites públicos, que permitem ao cidadão realizar um conjunto de serviços, principalmente no contexto do governo eletrônico (RAUPP; PINHO, 2014, p. 6). É indispensável que, após a institucionalização de um portal eletrônico, o mesmo seja acompanhado regularmente quanto à sua efetividade em relação ao público-alvo, pois, por meio deste acompanhamento, será possível identificar os ajustes necessários para que este canal cumpra com seu papel de dispor informações de modo a garantir total transparência na execução de políticas governamentais, despertando no cidadão a vontade de monitorar e acompanhar o desempenho dos gestores públicos (SANTOS et al., 2013).

Os portais eletrônicos devem ser planejados e estabelecidos de forma a facilitar o acesso dos cidadãos às informações, considerando que "o cidadão bem informado tem melhores condições de conhecer e acessar outros direitos essenciais, como saú-

\footnotetext{
${ }^{4}$ Para Sell et al. (2018), o termo accountability, traduzido para o português como "prestação de contas" e "responsável", não corresponde à totalidade da conceituação aplicada ao contexto brasileiro. Os autores ressaltam a necessidade da accountability por meio do acompanhamento e fiscalização dos atos gerados pelos agentes públicos. Accountability, em sentido restrito, é entendida como transparência dos atos e fatos governamentais disponibilizados na rede mundial de computadores.
} 
de, educação e benefícios sociais" (PIRES et al., 2013, p. 134). Além disso, em âmbito municipal o distanciamento entre o poder público e o cidadão é menor que a distância com as instâncias estadual e federal. Este distanciamento pode variar de acordo com o tamanho do município, mas sempre oferece a possibilidade de contato direto entre a administração pública e a sociedade, tendo em vista que o município se constitui em um espaço que privilegia a convivência das pessoas e grupos sociais, porque grande parte de seus problemas básicos estão inter-relacionados (JAMBEIRO; SOBREIRA; MACAMBIRA, 2012).

Obedecendo a legislação vigente, o ente público é obrigado a divulgar seus atos, baseando-se nos princípios que regem a gestão pública (legalidade, impessoalidade, moralidade, publicidade e eficiência). Desta forma, a transparência torna-se um dos fragmentos da publicidade, garantida pela Lei Complementar 131/2009 - Lei da Transparência -, que no artigo 1을 define que a transparência será assegurada mediante 0 incentivo à participação popular, liberação ao pleno conhecimento e acompanhamento da sociedade, em tempo real, de informações pormenorizadas sobre a execução orçamentária e financeira, em meios eletrônicos de acesso público ou adoção de sistema integrado de administração financeira e controle, que atenda a padrão mínimo de qualidade estabelecido pelo Poder Executivo da União (BRASIL, 2009).

A transparência engloba mais que o princípio da publicidade, previsto na Constituição Federal de 1988, pois traz a possibilidade da participação do cidadão na gestão pública, permitindo ao mesmo conhecer e intervir nos projetos, planos e ações públicas. Seu propósito é vedar ações imprevistas e impróprias, como o uso indevido do patrimônio público por parte dos gestores, ampliando o acesso dos cidadãos às informações públicas, em todas as esferas, com a finalidade de construir um país mais democrático, propiciando à sociedade desempenhar o controle social, colaborando na efetivação de uma gestão mais eficaz e eficiente (SOUZA et al., 2009).

Segundo Gomes Filho (2005), ao instituir qualquer política de transparência na gestão pública deve-se considerar duas perspectivas, sendo a primeira relacionada à disposição de abertura por parte de quem é detentor do poder, no sentido de retirar obstáculos ao acesso à informação por parte daqueles sobre quem o poder é exercido, e a segunda referente à disposição de informar, disponibilizando informações suficientes à visibilidade do poder diante daqueles sobre quem ele se exerce.

Nesse ínterim, a transparência é capaz de melhorar as relações entre a gestão pública e a sociedade, ocasionando benefícios como a inibição da corrupção governamental, maior prestação de contas e menor assimetria informacional entre os cidadãos e os gestores públicos (CUCCINIELLO; PORUMBESCU; GRIMMELIKHUIJSEN, 2017; SANTOS; VISENTINI, 2018). A transparência traz à sociedade o conhecimento das ações adotadas pelos governantes, das políticas introduzidas e dos recursos mobilizados.

Para Raupp e Zuccolotto (2015), o alastramento da informação pública constitui-se em condição fundamental para o êxito do ciclo da accountability, pois, caso os cidadãos tenham informações incompletas sobre as ações do poder público, enfrentarão dificuldades na avaliação do desempenho de seus representantes (governo). O objetivo da transparência deve ser garantir ao cidadão, de forma individual, o acesso às informações que transmitam o desempenho dos governantes, explicitando as ações que estão em andamento, as executadas em períodos anteriores e as que estão em fase de pla- 
nejamento, mediante a ampla divulgação por meio eletrônico e realização de audiências públicas, onde devem ser disponibilizados os planos, diretrizes orçamentárias, orçamentos, relatórios periódicos da execução orçamentária e da gestão fiscal, bem como das prestações de contas e pareceres prévios emitidos pelos tribunais de contas. A informação deve estar disponível a qualquer tempo, posto que um governo transparente não se limita apenas a disponibilizar informações relacionadas à sua gestão, mas também a deixar disponíveis informações de gestões anteriores à sua, para que os cidadãos tenham a possibilidade de traçar um paralelo que lhes permita acompanhar a evolução da máquina pública (SILVA, 2009).

Além das investigações de Cruz et al. (2012), Costa et al. (2016) e Rossoni e Beiruth (2016), outros trabalhos buscaram mensurar a transparência na gestão pública, no intuito de apresentar à sociedade a situação real da transparência e de como as informações estão sendo disponibilizadas. No estudo de Cruz (2010) sobre a transparência da gestão pública dos grandes municípios brasileiros, foram investigados os portais eletrônicos dos 96 municípios incluídos entre os cem mais populosos do Brasil; o resultado encontrado foi uma média geral para o ITGP-M de 66,10, com distribuição dispersa, pois dos 143 pontos possíveis dos municípios investigados, o com menor pontuação obteve 15 pontos (Carapicuíba - SP) e o município com maior índice alcançou 122 pontos (Londrina - PR). Esses resultados, por serem encontrados nos maiores municípios brasileiros em termos populacionais, que reunidos correspondem a $60 \%$ do PIB brasileiro, revelam níveis de transparência de informações da gestão pública municipal bastante baixos, se comparados com a produção de riqueza advinda dos respectivos municípios (CRUZ, 2010).

Rossoni (2013) investigou a transparência na gestão pública municipal em municípios do Estado do Espírito Santo, com o objetivo de identificar quais Prefeituras eram mais transparentes na divulgação de informações em seus portais eletrônicos e quais características explicavam o nível de transparência observado. A autora encontrou uma média geral do ITGP-M de 27 pontos, bem distante do máximo possível (143 pontos). As Prefeituras que obtiveram menor pontuação alcançaram zero e a que atingiu maior índice registrou 85 pontos. Nesse estudo, 36\% dos municípios apresentaram pontuação menor ou igual a 15 pontos, $64 \%$ acima de 15 e 50\% dos municípios apresentaram pontuação entre 12 e 37 pontos (ROSSONI, 2013).

Ainda, sob a perspectiva do ITGP-M, Costa e Torres (2015) analisaram a realidade dos municípios paraibanos com mais de 10.000 habitantes, constatando que o fato de existir o portal institucional não significa que, necessariamente, o ente público estará disponibilizando informações relevantes por meio dele, como prevê a legislação. Dentre os 72 portais investigados pelos autores, o que obteve maior pontuação no ITGP-M foi o de João Pessoa (68), correspondendo a 48\% do máximo possível, 143. Os demais municípios alcançaram no máximo $30 \%$ do índice, pelo fato de não disponibilizarem as informações básicas em seus portais.

\section{MÉTODO DO ESTUDO}

Para a concretização do estudo realizou-se um censo, coletando dados nos portais eletrônicos das 25 Prefeituras que pertencem ao Corede Missões (Figura 1). 
Figura 1 - Localização dos municípios no Corede Missões

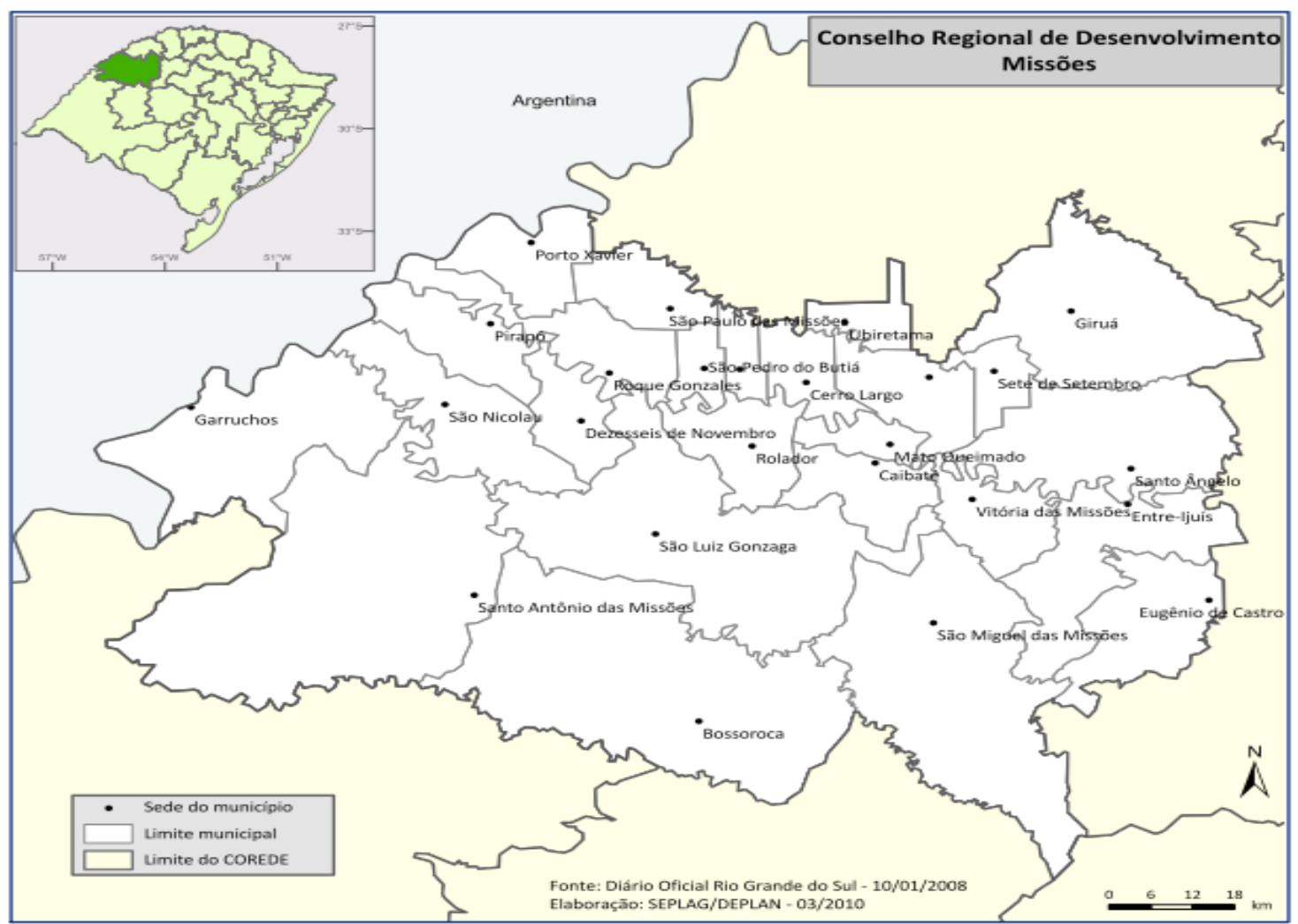

Fonte: ATLAS SOCIOECONÔMICO DO RS (2018).

A exploração dos portais eletrônicos orientou-se no ITGP-M elaborado por Cruz (2010). Para a coleta de informações foi desenvolvido um banco de dados com a utilização do Microsoft Excel, no qual as informações, colhidas no período de outubro de 2016 a janeiro de 2017, foram registradas e armazenadas em planilha eletrônica. Para identificação dos portais eletrônicos dos municípios, optou-se pela plataforma de busca on-line do Google (http://www.google.com.br), utilizando-se como termo padrão de busca "Prefeitura Municipal de (nome do município)".

Foram usadas cerca de 300 horas para análise dos portais, sendo gasto em média 12 horas em cada portal eletrônico, pois na identificação das 119 variáveis investigadas foram encontradas inúmeras dificuldades, por exemplo se no portal existia mapa do site. Como na maioria dos municípios esse recurso não era disponibilizado, partia-se para o serviço de busca, quando este era disponibilizado. Não encontrando o serviço de busca, acessavam-se os links disponíveis na página principal, e, caso ainda não encontrasse o conteúdo procurado, acessava-se a plataforma de busca on-line do Google e digitava-se o que estava se procurando e o nome do município, como "Código Tributário do município de (nome do município)". Somente após descartadas todas essas hipóteses, considerava-se como não disponibilizadas as informações pelo município.

A pontuação de análise atribuída foi de zero a 143, conforme metodologia do ITGP-M, a qual quantifica a transparência municipal no valor máximo de 143 pontos, divididos em 6 categorias de informações, avaliando desde informações básicas até financeiras, fiscais, contábeis, quantitativas e qualitativas sobre a gestão, conforme apresentado no Quadro 1. 
Quadro 1 - Categorias de informações constantes do ITGP-M

\begin{tabular}{|c|c|c|c|c|}
\hline Categoria & $\begin{array}{l}\text { Categorias de in- } \\
\text { formações }\end{array}$ & $\begin{array}{c}\text { Quantidade } \\
\text { de itens }\end{array}$ & $\begin{array}{c}\text { Pontuação } \\
\text { Máxima }\end{array}$ & Objetivos da divulgação \\
\hline $\mathrm{C} 1$ & $\begin{array}{l}\text { Informações gerais } \\
\text { sobre o município e } \\
\text { prefeito }\end{array}$ & 8 itens & 10 & $\begin{array}{l}\text { Prover o cidadão de informações básicas } \\
\text { sobre os ocupantes de cargos eleitos e a } \\
\text { estrutura administrativa municipal. }\end{array}$ \\
\hline $\mathrm{C} 2$ & $\begin{array}{l}\text { Legislação munici- } \\
\text { pal e Instrumentos } \\
\text { de planejamento } \\
\text { municipal }\end{array}$ & 11 itens & 11 & $\begin{array}{l}\text { Prover ao cidadão acesso à legislação mu- } \\
\text { nicipal ordinária e também aos instrumen- } \\
\text { tos de planejamento que orientam a ges- } \\
\text { tão orçamentária (receitas e despesas). }\end{array}$ \\
\hline $\mathrm{C} 3$ & $\begin{array}{l}\text { Informações finan- } \\
\text { ceiras, relatórios } \\
\text { contábeis e fiscais }\end{array}$ & 16 itens & 36 & $\begin{array}{l}\text { Prover ao cidadão acesso aos principais re- } \\
\text { latórios sobre a situação econômico-finan- } \\
\text { ceira do município no tocante à execução } \\
\text { do orçamento, gestão dos ativos e das dívi- } \\
\text { das do município. }\end{array}$ \\
\hline C4 & $\begin{array}{l}\text { Interação com os } \\
\text { cidadãos e } \\
\text { com a sociedade }\end{array}$ & 17 itens & 19 & $\begin{array}{l}\text { Prover ao cidadão informações sobre os } \\
\text { serviços prestados on-line no portal do } \\
\text { município, as possibilidades de interação e } \\
\text { participação na definição das preferências } \\
\text { governamentais. }\end{array}$ \\
\hline C5 & $\begin{array}{l}\text { Análise do portal } \\
\text { do município }\end{array}$ & 7 itens & 7 & $\begin{array}{l}\text { Possibilitar uma análise das condições de } \\
\text { acessibilidade e navegabilidade do portal } \\
\text { do município. }\end{array}$ \\
\hline $\mathrm{C} 6$ & $\begin{array}{l}\text { Informações quan- } \\
\text { titativas e qualita- } \\
\text { tivas sobre a gestão }\end{array}$ & 60 itens & 60 & $\begin{array}{l}\text { Prover o cidadão de informações claras e } \\
\text { objetivas em áreas consideradas de maior } \\
\text { interesse e cujas condições têm impacto } \\
\text { direto na vida dos cidadãos: política tri- } \\
\text { butária, administração, licitações e com- } \\
\text { pras, segurança pública, educação, cultura, } \\
\text { esporte e lazer, habitação e urbanismo, } \\
\text { saúde, saneamento básico, gestão am- } \\
\text { biental, atividades econômicas (indústria, } \\
\text { comércio, serviços e agricultura), trabalho } \\
\text { e transportes. }\end{array}$ \\
\hline
\end{tabular}

Fonte: CRUZ (2010, p. 85).

Assim, o ITGP-M constitui-se em uma variável de natureza quantitativa que pode variar de zero a 143 pontos. A pontuação que cada Prefeitura recebeu foi o somatório de cada uma das categorias, podendo ser representado pela seguinte expressão:

$$
\text { ITGP-M }=\sum \mathrm{C} 1+\sum \mathrm{C} 2+\sum \mathrm{C} 3+\sum \mathrm{C} 4+\sum \mathrm{C} 5+\sum \mathrm{C} 6
$$

Os itens contemplados no instrumento de coleta de dados foram analisados a partir de uma lógica binária, posto que a existência no site levou à pontuação 1 (um) e a não existência à pontuação zero. Como, porém, alguns itens da categoria 3 (C3) contemplam relatórios periódicos de publicação obrigatória pelas prefeituras, ${ }^{5}$ para esses demonstrativos a pontuação por sua disponibilização considera uma escala proporcional, que usa como referência a periodicidade máxima dos relatórios previstos pela Lei de

\footnotetext{
${ }^{5}$ Relatórios periódicos de publicação obrigatória pelas prefeituras, tais como: prestações de contas, Balanço Patrimonial, Balanço Orçamentário, Balanço Financeiro e Demonstração das Variações Patrimoniais; além dos relatórios previstos na Lei no 101/2000 (BRASIL, 2000), Relatório Resumido da Execução Orçamentária (RREO) - seus anexos e sua versão simplificada, Relatório da Gestão Fiscal (RGF) - seus anexos e versão simplificada e também os pareceres prévios emitidos pelos tribunais de contas em relação às prestações de contas anuais.
} 
Responsabilidade Fiscal (LRF), que são maioria na categoria C3, pelo fato de o número máximo dos relatórios previstos da LRF ser equivalente a dez anos e exigidos desde o ano de 2000 (CRUZ, 2010). Estes critérios estão estabelecidos no Quadro 2.

Quadro 2 - Critérios de pontuação dos itens periódicos do modelo de investigação

\begin{tabular}{|c|c|}
\hline Parâmetro & Pontuação \\
\hline $1-3$ anos & 1 ponto \\
\hline $4-6$ anos & 2 pontos \\
\hline $7-10$ anos & 3 pontos \\
\hline
\end{tabular}

Fonte: CRUZ (2010, p. 86).

Após a coleta de dados e a obtenção do resultado do somatório das categorias avaliadas, realizou-se o cálculo de uma regra de três simples para transformar os 143 pontos máximos possíveis em um resultado de $100 \%$ de transparência, sendo de $1 \%$ a $25 \%$ considerados níveis péssimos de transparência, de $25 \%$ a 50\% níveis regulares, de $50 \%$ a $75 \%$ níveis bons e de 75\% a 100\% considerados níveis excelentes de transparência.

\section{ANÁLISE DOS RESULTADOS}

Nesta seção apresenta-se o ITGP-M evidenciado nos Portais Eletrônicos dos municípios do Corede Missões, indicador formado por 119 variáveis, divididas em seis categorias, que mensura a situação da transparência evidenciada nos respectivos portais eletrônicos. Os dados da Tabela 1 indicam, de modo geral, a pontuação média dos municípios para cada uma das categorias do ITGP-M.

Tabela 1 - Categorias e pontuação do instrumento de coleta de dados

\begin{tabular}{|c|c|c|c|c|}
\hline Categoria & $\begin{array}{l}\text { Pontuação } \\
\text { máxima } \\
\text { possível } \\
\text { na escala }\end{array}$ & $\begin{array}{l}\text { Pontuação má- } \\
\text { xima observa- } \\
\text { da nos portais } \\
\text { eletrônicos } \\
\text { investigados }\end{array}$ & Média & $\begin{array}{l}\text { Desvio } \\
\text { Padrão }\end{array}$ \\
\hline $\begin{array}{l}\mathrm{C} 1 \text { - Informações gerais sobre } \\
\text { o município, gestor municipal e } \\
\text { vereadores }\end{array}$ & 10 & 9 & 5,28 & 1,86 \\
\hline $\begin{array}{l}\mathrm{C} 2 \text { - Legislação } \\
\text { instrumentos de planicipal ejamento } \\
\text { municipal }\end{array}$ & 11 & 11 & 7,32 & 2,73 \\
\hline $\begin{array}{l}\text { C3 - Informações financeiras, } \\
\text { relatórios contábeis e fiscais }\end{array}$ & 36 & 30 & 17,44 & 5,29 \\
\hline $\begin{array}{l}\text { C4 - Interação com o cidadão e com } \\
\text { a sociedade }\end{array}$ & 19 & 8 & 4,28 & 1,81 \\
\hline C5 - Análise do portal do município & 7 & 4 & 3,04 & 1,05 \\
\hline $\begin{array}{l}\text { C6 - Disponibilização aos cidadãos } \\
\text { de informações quantitativas e } \\
\text { qualitativas sobre a gestão }\end{array}$ & 60 & 30 & 16,32 & 5,39 \\
\hline Total Geral (ITGP-M) & 143 & 92 & 53,68 & 18,13 \\
\hline
\end{tabular}

Fonte: Dados da pesquisa (2017). 
A Categoria de Informação C1 tem o objetivo de prover o cidadão de informações básicas sobre os ocupantes de cargos eleitos e a estrutura administrativa municipal, e averigua se estão sendo disponibilizadas nos portais eletrônicos dos municípios informações sobre os órgãos municipais e seus responsáveis, sobre autarquias e/ou empresas municipais, sobre o planejamento estratégico municipal, filiação político-partidária dos eleitos para os Poderes Executivo e Legislativo, informações biográficas e profissionais sobre o prefeito, secretários e vereadores do município e suas respectivas remunerações. O que foi observado é que nos portais eletrônicos divulgam-se informações básicas sobre a estrutura administrativa dos municípios, seus gestores e endereço eletrônico para contato com estes. Quando se trata de fornecer informações sobre remuneração, biografia e partido político, nem todos os municípios o fazem, sendo $60 \%$ os que divulgam a remuneração, $36 \%$ os que informam o partido político a que estão vinculados e apenas $16 \%$ os que têm informações biográficas sobre seus gestores. Nenhum dos municípios obteve a pontuação máxima nesse item, que indicou de 5,28 e desvio-padrão de 1,86, o qual, considerando a escala utilizada, não indica alta variabilidade de pontuação dos municípios em relação à média. Tal resultado mostra que, de um modo geral, a pontuação do ITGP-M, para a maioria dos municípios, foi baixa, uma vez que $76 \%$ deles obteve pontuação inferior a 6.

Na categoria C2, que trata da legislação municipal e dos instrumentos de planejamento municipal, os quais podem ser utilizados pelos cidadãos de acordo com as normas de boas práticas de governança para a participação e o controle social, percebe-se que a maioria dos municípios (70\%) publica a legislação ordinária, bem como suas respectivas leis orgânicas, planos diretores, planos plurianuais (PPAs), leis de diretrizes orçamentárias (LDOs), leis orçamentárias anuais (Loas) e divulgações de alterações no orçamento (como o caso de créditos adicionais aprovados pelo Legislativo Municipal). Tem-se como resultado média de 7,32 (desvio-padrão de 2,73 ), que pode ser considerada alta para a categoria.

O grupo da categoria C3, sobre informações financeiras e relatórios contábeis e fiscais, tem o objetivo de possibilitar ao cidadão o acesso aos principais relatórios sobre a situação econômico-financeira do município, e é constituído por questões que contemplam relatórios de prestação de contas, balanço orçamentário, balanço patrimonial, balanço financeiro, demonstração das variações patrimoniais, relatórios resumidos da execução orçamentária (RREO), relatório de gestão fiscal (RGF), parecer prévio emitido pelo Tribunal de Contas referente às prestações de contas do último exercício, divulgação da política de controle interno, dívida municipal e informações sobre sua evolução, destinação das operações de crédito realizadas pelo município, dentre outras informações. Nos municípios avaliados, da pontuação máxima possível (36), a máxima observada foi 30. No geral, trata-se de uma distribuição dispersa, com média 17,44 e desvio padrão 5,29, indicando que há uma alta variabilidade na pontuação geral dos municípios para esta categoria, sendo a pontuação mínima observada igual a 11.

A categoria C4 - interação com os cidadãos e com a sociedade - conta com 17 questões que averiguam quais informações são disponibilizadas nos portais eletrônicos das prefeituras, com o objetivo de possibilitar aos cidadãos a participação na gestão, bem como o controle social. Dentre os itens verificados, constatou-se que nenhum dos municípios reserva em seu portal eletrônico um espaço para o cadastro e divulgação de 
associação de bairros/moradores; não divulgam se possuem um código ou regulamento de participação popular na gestão municipal, nem mesmo a forma da participação dos cidadãos na elaboração do orçamento municipal, tampouco o calendário das audiências públicas quadrimestrais para avaliação das metas fiscais, as quais são de obrigatoriedade do Poder Executivo, em obediência à LRF (artigo 9요, §4ㅇ). Neste grupo de informações a pontuação máxima possível é 19 e a máxima alcançada pelos municípios foi de 8 , o que representa $42 \%$ do total, com média de 4,28 e desvio padrão 1,81 , indicando que há grande convergência entre os municípios investigados em ter baixa pontuação para esta categoria.

Na categoria (C5) na qual foi realizada a análise do portal do município, no que diz respeito as condições de acessibilidade e navegabilidade, foi observado que nenhum município possui a ferramenta "mapa do site", não oferece informações em outros idiomas, nem acessibilidade a portadores de necessidades especiais, não atendendo desta forma as "Recomendações para acessibilidade do conteúdo da Web" (WCAG2.0), uma norma internacional que objetiva orientar as regras de acessibilidade do conteúdo da Web, a fim de torná-lo acessível (DA SILVA ALVES; FERREIRA, 2011). Estas recomendações, quando levadas em consideração, permitem que as informações disponibilizadas estejam também acessíveis para cidadãos portadores de deficiências, dentre as quais dificuldades sensoriais, cognitivas, motoras, auditivas, visuais, de aprendizagem, entre outras. Assim, como eram 7 os itens que compunham esta categoria de análise e 3 deles são negligenciados por $100 \%$ dos municípios, a pontuação máxima possível foi de 7 , sendo a máxima observada de 4 e a mínima 0, com média de 3,04 e desvio padrão de 1,05 , o qual indica uma alta concentração de municípios com pontuação bastante próxima à média.

Finalizando, a categoria (C6) apresenta as informações quantitativas e qualitativas sobre a gestão, com o intuito de prover ao cidadão informações claras e objetivas em áreas consideradas de maior interesse e cujas condições têm impacto direto em suas vidas, especificamente política tributária, administração, licitações e compras, segurança pública, educação, cultura, esporte e lazer, habitação e urbanismo, saúde, saneamento básico, gestão ambiental, atividades econômicas (indústria, comércio, serviços e agricultura), trabalho e transportes. A pontuação máxima possível para este grupo de informações é 60 , a máxima alcançada foi 30, com média 16,32 e desvio padrão de 5,39, indicando alta variabilidade na pontuação dos municípios com relação à média geral.

Nessa análise, constatou-se que a média geral do ITGP-M foi de 53,68, posto que o município com menor pontuação obteve 35 pontos (Dezesseis de Novembro), enquanto o maior índice foi de 76 pontos (obtido pelo município de São Luiz Gonzaga). Apesar de a realidade da presente investigação distinguir-se das levantadas por Cruz (2010), Costa e Torres (2015) e Rossoni (2013), por analisar a transparência na gestão pública municipal na região de abrangência do Corede Missões/RS, em que a maioria dos municípios é de pequeno porte, com população inferior a 10.000 habitantes, os resultados encontrados são semelhantes e revelam que os sites dos municípios investigados configuram-se mais como murais eletrônicos do que como espaços de construção de accountability, por meio da disponibilização de informações sobre a gestão pública.

A Tabela 2 relaciona os municípios investigados, possibilitando uma visualização daqueles mais bem posicionados no ranking de transparência, na perspectiva do ITGP-M. 
Tabela 2 - Ranking dos municípios de acordo com o ITGP-M

\begin{tabular}{|c|c|c|c|c|c|c|c|c|c|}
\hline \multicolumn{10}{|c|}{ Pontuação por Categoria de Informação } \\
\hline Município & C1 & C2 & C3 & C4 & $\mathrm{C} 5$ & C6 & ITGP-M & $\%$ & Classificação \\
\hline São Luiz Gonzaga & 6 & 9 & 22 & 5 & 4 & 30 & 76 & 53,1 & 10 \\
\hline São Miguel das Missões & 7 & 10 & 29 & 4 & 3 & 21 & 74 & 51,7 & 20 \\
\hline São Paulo das Missões & 5 & 10 & 20 & 7 & 4 & 25 & 71 & 49,6 & $3 ㅇ$ \\
\hline Santo Ângelo & 6 & 11 & 19 & 6 & 4 & 24 & 70 & 48,9 & 40 \\
\hline Giruá & 9 & 7 & 19 & 7 & 3 & 21 & 66 & 46,1 & 5은 \\
\hline Porto Xavier & 7 & 9 & 21 & 3 & 4 & 17 & 61 & 42,6 & 60 \\
\hline Mato Queimado & 3 & 9 & 22 & 6 & 4 & 17 & 61 & 42,6 & 70 \\
\hline Pirapó & 4 & 3 & 30 & 3 & 3 & 15 & 58 & 40,5 & 80 \\
\hline Guarani das Missões & 7 & 4 & 22 & 5 & 3 & 16 & 57 & 39,8 & 9음 \\
\hline São Pedro do Butiá & 2 & 10 & 21 & 4 & 3 & 17 & 57 & 39,8 & 10 o \\
\hline Entre-ljuís & 4 & 10 & 16 & 3 & 3 & 21 & 57 & 39,8 & 110 \\
\hline Caibaté & 5 & 10 & 12 & 5 & 4 & 16 & 52 & 36,3 & 120 \\
\hline Ubiretama & 3 & 9 & 12 & 8 & 3 & 17 & 52 & 36,3 & 13 은 \\
\hline Eugênio de Castro & 2 & 9 & 24 & 2 & 1 & 13 & 51 & 35,6 & 140 \\
\hline Vitória das Missões & 6 & 6 & 13 & 4 & 4 & 17 & 50 & 34,9 & 15 응 \\
\hline Cerro Largo & 6 & 6 & 17 & 2 & 4 & 15 & 50 & 34,9 & 160 \\
\hline Bossoroca & 5 & 9 & 18 & 4 & 1 & 12 & 49 & 34,2 & 170 \\
\hline Rolador & 3 & 8 & 16 & 5 & 3 & 13 & 48 & 33,5 & 180 \\
\hline Sete de Setembro & 6 & 9 & 12 & 1 & 0 & 18 & 46 & 32,1 & 19 은 \\
\hline Salvador das Missões & 8 & 6 & 12 & 7 & 2 & 11 & 46 & 32,1 & 200 \\
\hline Roque Gonzales & 4 & 6 & 16 & 4 & 3 & 13 & 46 & 32,1 & 210 \\
\hline São Nicolau & 6 & 4 & 12 & 4 & 3 & 15 & 44 & 30,7 & 220 \\
\hline Garruchos & 5 & 1 & 16 & 2 & 3 & 11 & 38 & 26,5 & 230 \\
\hline Santo Antônio das Missões & 8 & 4 & 11 & 3 & 4 & 7 & 37 & 25,8 & 240 \\
\hline Dezesseis de Novembro & 5 & 4 & 14 & 3 & 3 & 6 & 35 & 24,4 & 25 음 \\
\hline
\end{tabular}

Fonte: Dados da pesquisa (2017).

Com base na Tabela 2 pode-se inferir que os municípios não alcançaram o máximo esperado nas categorias que compõem o ITGP-M. São Luiz Gonzaga foi classificado como o município mais transparente da região em análise, obtendo um índice de $53 \%$ na avaliação de seu portal, ou seja, 76 pontos do total do ITGP-M, enquanto Dezesseis de Novembro foi o município considerado com menor índice de transparência na divulgação de informações sobre sua gestão, alcançando um índice de $24 \%$, ou seja, 35 pontos. Alguns municípios destacaram-se em categorias de avaliação distintas, conforme apresentado no Quadro 3.

Observando o Quadro 3 pode-se discorrer sobre algumas das potencialidades e fragilidades apresentadas pelos municípios avaliados. Giruá destacou-se na Categoria 1, disponibilizando 7 dos 8 itens avaliados. Distinguiu-se dos demais por ser o que mais disponibilizou informações gerais sobre o município e o gestor municipal, apresentando, em seu portal eletrônico, informações detalhadas sobre os órgãos municipais, suas funções e seus responsáveis; endereço eletrônico para o contato com as secretarias municipais, informações sobre a filiação político-partidária dos eleitos para o Poder Execu- 
tivo, bem como informações biográficas do prefeito, e-mail e formulário para contato com o prefeito e secretários municipais, além de expor dados sobre a remuneração do prefeito, secretários e demais servidores municipais.

Quadro 3 - Análise de acordo com as categorias do ITGP-M

\begin{tabular}{|c|c|c|c|c|}
\hline \multicolumn{5}{|c|}{ Subitens do Instrumento de Coleta de dados } \\
\hline \multirow{7}{*}{$\begin{array}{l}\sum_{i} \\
\text { j్ } \\
\text { E }\end{array}$} & Categoria & $\begin{array}{l}\text { Máximo } \\
\text { possível }\end{array}$ & $\begin{array}{l}\text { Máximo } \\
\text { observado } \\
\text { nos portais } \\
\text { eletrônicos } \\
\text { investigados }\end{array}$ & $\begin{array}{l}\text { Município que obteve o } \\
\text { maior índice na categoria }\end{array}$ \\
\hline & $\begin{array}{l}\text { C1 - Informações gerais sobre } \\
\text { o município, gestor municipal } \\
\text { e vereadores }\end{array}$ & 10 & 9 & Giruá \\
\hline & $\begin{array}{l}\text { C2 - Legislação municipal e } \\
\text { instrumentos de planejamento } \\
\text { municipal }\end{array}$ & 11 & 11 & Santo Ângelo \\
\hline & $\begin{array}{l}\text { C3 - Informações financeiras, } \\
\text { relatórios contábeis e fiscais }\end{array}$ & 36 & 30 & Pirapó \\
\hline & $\begin{array}{l}\text { C4 - Interação com o cidadão } \\
\text { e com a sociedade }\end{array}$ & 19 & 8 & Ubiretama \\
\hline & $\begin{array}{l}\text { C5 - Análise do portal do } \\
\text { município }\end{array}$ & 7 & 4 & $\begin{array}{l}\text { São Luiz Gonzaga, São } \\
\text { Paulo das Missões, Santo } \\
\text { Ângelo, Porto Xavier, Mato } \\
\text { Queimado, Caibaté, Vitória } \\
\text { das Missões, Cerro Largo e } \\
\text { Santo Antônio das Missões }\end{array}$ \\
\hline & $\begin{array}{l}\text { C6 - Disponibilização aos } \\
\text { cidadãos de informações } \\
\text { quantitativas e qualitativas } \\
\text { sobre a gestão }\end{array}$ & 60 & 30 & São Luiz Gonzaga \\
\hline
\end{tabular}

Fonte: Dados da pesquisa (2017).

Já o município de Santo Ângelo teve destaque na Categoria 2, destacando no site todos os 11 itens avaliados neste grupo de informações, sendo eles: a legislação ordinária do município; a Lei Orgânica Municipal; o Plano Diretor de Desenvolvimento Municipal; o Plano Plurianual (PPA) em vigor; PPAs anteriores, com vigência esgotada; a Lei de Diretrizes Orçamentárias (LDO) em vigência; LDOs de anos anteriores; a Lei Orçamentária Anual (LOA) em vigor e de anos anteriores; divulgação das alterações no orçamento (por exemplo os créditos adicionais) aprovadas pelo Legislativo Municipal; e divulgação dos orçamentos e/ou prestações de contas dos órgãos descentralizados ou empresas municipais. Esse grupo de informações permite ao cidadão o acesso a todos os instrumentos de planejamento que orientam a gestão orçamentária do município, para que, com essas informações, caso queira participar da gestão, possa fazê-lo, exercendo o controle. Giacomoni (2012) apresenta a relação entre o planejamento e o orçamento como uma oportunidade de sistematização entre os programas e projetos do Estado e as metas estabelecidas neles, além de direcionar sua execução com base nos recursos empregados, o que permite um processo rigoroso de avaliação e controle, por sua vez, assegurados pela LRF. 
O município de Pirapó destacou-se na Categoria 3, sendo o que mais evidenciou no portal eletrônico informações financeiras e relatórios contábeis e fiscais. A divulgação deste tipo de informação foi imposta pela LRF, que, em seu artigo 48, determina os instrumentos de transparência da gestão fiscal: os planos, orçamentos e leis de diretrizes orçamentárias; as prestações de contas e o respectivo parecer prévio; o Relatório Resumido da Execução Orçamentária (RREO) e o Relatório de Gestão Fiscal (RGF); e as versões simplificadas desses documentos. Segundo este normativo, estes instrumentos devem ser amplamente divulgados para os cidadãos pelos meios oficias de comunicação, além de disponibilizá-lo em meios eletrônicos de acesso público. Tanto o RREO quanto o RGF tratam-se de demonstrativos que têm como objetivo demonstrar periodicamente a situação orçamentária e financeira dos órgãos públicos, posto que os seus resultados indicam o cumprimento (ou não) das metas ficais (BRASIL, 2000). Para Paiva e Zuccolotto (2009), a transparência da gestão fiscal relaciona-se ao "fluxo crescente e tempestivo de informação econômica, social e política sobre a administração municipal em meios eletrônicos de acesso público", o que significa a possibilidade, por parte do cidadão, do acompanhamento transparente da execução orçamentária e das finanças públicas (CRUZ, 2010). Pelo fato de os relatórios e demonstrativos criados a partir da LRF constituírem-se em ferramentas de controle de difícil compreensão inclusive para profissionais da área contábil, o ideal seria que as informações neles contidas sejam traduzidas para a parte mais interessada: os cidadãos.

Na categoria 4, o município que obteve maior pontuação foi Ubiretama, que atingiu 8 dos 19 pontos possíveis. No geral, o índice de evidenciação de informações desta categoria foi baixo, indicando que há baixa divulgação de informações que possibilitem aos cidadãos um maior controle social, bem como a sua participação na gestão, o que corrobora o estudo de Raupp e Pinho (2013), os quais concluíram que os portais eletrônicos investigados de câmaras municipais do Estado de Santa Catarina, configuram-se, predominantemente, como murais eletrônicos, "em resposta a um impulso da modernidade expresso por um imperativo tecnológico dominante, porém não contribuindo para o desenvolvimento democrático" (p. 770).

As questões disponíveis na Categoria 5 indicam as condições de acessibilidade e navegabilidade do portal. Neste grupo foi verificado: se no portal eletrônico havia a ferramenta de "Mapa do site" para facilitar a busca de informações por parte do cidadão; se existia ferramenta de busca do conteúdo por meio de palavras-chaves; se as informações são disponibilizadas em outros idiomas; se é divulgado endereço eletrônico (e-mail) ou formulário de contato institucional para registro de reclamações, comentários e sugestões; se está disponível o serviço de Ouvidoria on-line; se o conteúdo do portal eletrônico é atualizado (frequência mínima semanal); e se oferece acessibilidade a portadores de necessidades especiais. A pontuação máxima possível nesta categoria é de sete pontos, considerando-se que os municípios que mais pontuaram alcançaram quatro pontos, sendo eles: São Luiz Gonzaga, São Paulo das Missões, Santo Ângelo, Porto Xavier, Mato Queimado, Caibaté, Vitória das Missões, Cerro Largo e Santo Antônio das Missões.

Por fim, o município de São Luiz Gonzaga destacou-se na Categoria 6, a qual verifica se os municípios disponibilizam aos cidadãos informações quantitativas e qualitativas sobre a gestão, investigando a presença nos sites da política tributária do município, infor- 
mações sobre a administração de pessoal, licitações e compras públicas, segurança pública, educação, cultura, esporte e lazer, habitação e urbanismo, saúde, saneamento básico, gestão ambiental, indústria, comércio e serviços, agricultura, trabalho e transporte. Do máximo possível de 60 pontos, São Luís Gonzaga alcançou 30, enquanto os demais municípios obtiveram índices bem menores. Esta categoria influenciou a posição no ranking da transparência de acordo com o ITGP-M, pois, das 119 variáveis investigadas, 59 faziam parte desta categoria. O resultado encontrado corrobora o da pesquisa do Ministério Público Federal (2016), que avaliou os portais de transparência de 5.567 municípios e 26 Estados, além do Distrito Federal, com o objetivo de medir o grau de cumprimento da legislação da Transparência e de Acesso à Informação, por meio de um questionário elaborado pela Estratégia Nacional de Combate à Corrupção e à Lavagem de Dinheiro (ENCCLA), o qual, numa escala de zero a 10 para medir o atendimento dos portais em relação à legislação, atribuiu ao município de São Luiz Gonzaga nota $10^{6}$ (MPF, 2016).

Assim, após evidenciar nos portais eletrônicos a transparência na gestão pública e criar um ranking da transparência dos municípios integrantes do Corede Missões, têm-se um diagnóstico que pode possibilitar aos cidadãos observar o desempenho dos gestores de seus municípios, eleitos por eles, e ponderar sobre a eficiência na gestão pública e a suficiência ou não das informações disponibilizadas e, assim, exercer o controle social, participando da gestão.

\section{CONSIDERAÇÕES FINAIS}

O artigo se propôs a investigar a transparência na gestão pública nos municípios que integram o Corede Missões por meio dos portais eletrônicos, utilizando ranqueamento elaborado a partir da aplicação do ITGP-M. As principais contribuições do estudo revelam que a realidade dos municípios investigados não se apresenta de forma satisfatória no que diz respeito à transparência evidenciada em seus portais eletrônicos, sendo averiguado que nenhum dos municípios divulga completamente as informações acerca da gestão pública municipal.

Das seis categorias de informações que compõem o ITGP-M, em cinco delas não se observou atendimento a todos os itens. A média geral do índice foi de 53,68 (valor máximo de 143 pontos), posto que o município com menor pontuação obteve 35 pontos (Dezesseis de Novembro), enquanto o maior índice foi de 76 (obtido pelo município de São Luiz Gonzaga). Tal análise reflete que muitos dos portais dos municípios investigados configuram-se predominantemente como murais eletrônicos e não como espaços de construção da transparência, por meio da disponibilização de informações referentes aos atos e fatos da gestão pública. Tais portais possuem características meramente informativas dos órgãos e departamentos da Prefeitura, tornando coadjuvante o cumprimento de grande parte dos requisitos legais para o atendimento das demandas informacionais da sociedade.

Por mais que entre os investigados haja municípios que já tenham avançado na questão da transparência das suas ações, o que se percebe é que ainda há um longo caminho a ser percorrido para que esta seja tratada como uma questão de prioridade pela

${ }^{6} \mathrm{O}$ resultado desta pesquisa pode ser acessado no link http://rankingdatransparencia.mpf.mp.br/. 
gestão pública. Ficou claro que a divulgação dos dados e informações sobre a gestão pública não é totalmente feita em conformidade com a legislação, e há pouco incentivo à participação do cidadão nos processos de planejamento, acompanhamento e avaliação das ações do governo, o que não contribui para o controle social.

Os resultados encontrados contribuem no campo prático e teórico. Em termos práticos, apresenta-se um diagnóstico da transparência na gestão pública municipal no âmbito do Corede Missões, detalhado na avaliação de diferentes categorias de informações, cuja divulgação, de maneira satisfatória nos portais municipais, atesta a efetivação da transparência pública. A análise do desempenho obtido em cada categoria pelos gestores municipais, indica, pontualmente, quais aspectos da gestão municipal ainda necessitam de maior divulgação.

Os atores envolvidos, ao acompanharem as atividades da gestão pública, assumindo o papel de fiscalização, podem participar ativamente da gestão, intervindo no processo de formulação de políticas públicas, direcionando estas políticas para o bem-estar da comunidade envolvida, atendendo às demandas sob a ótica de quem conhece o ambiente onde vive. Assim, tanto a sociedade civil quanto gestores públicos podem utilizar-se dos resultados deste estudo, pois informação é poder e, munidos deste poder, outros direitos básicos podem ser acessados, como a saúde e a educação.

Teoricamente, a contribuição está relacionada à provocação de uma reflexão sobre a manifestação da transparência nos portais eletrônicos de municípios brasileiros, incentivando o acompanhamento e a fiscalização da gestão por parte dos cidadãos.

Cabe destacar que, ainda que o estudo tenha rigor metodológico, é necessário apontar suas limitações. O nível de transparência foi apurado pelos dados coletados nos portais eletrônicos mantidos pelas Prefeituras, as quais podem não apresentar o conteúdo de forma organizada e clara, dificultando o acesso. Outra limitação é o fato de no ano de 2016 ter ocorrido eleições para o pleito municipal, acarretando na mudança de governo na maioria dos municípios investigados. Quanto a isso, Cruz (2010) considera que a definição do que deve ser divulgado nos portais eletrônicos das entidades públicas, a título de evidenciação voluntária para que estas sejam consideradas transparentes, é uma questão passível de discussão.

Como sugestão para realização de outras pesquisas sobre o tema, recomenda-se: abordar a transparência utilizando outros instrumentos de mensuração; pesquisar sobre outras formas de se manifestar a transparência na gestão pública, além da internet; investigar a qualidade e a veracidade da informação disponibilizada pela gestão pública municipal; abordar a percepção dos usuários dos portais eletrônicos do governo para investigar qual a demanda de informações sobre a gestão pública; verificar como os cidadãos compreendem a transparência e qual a perspectiva da sociedade no relacionamento governo $x$ cidadão.

\section{AGRADECIMENTO}

Os autores agradecem ao CNPq pelo auxílio financeiro na realização da pesquisa (Processo № 405563/2016-7). 


\section{REFERÊNCIAS}

ALLEBRANDT, S. L. et al. Gestão social e cidadania deliberativa: uma análise da experiência dos Coredes no Rio Grande do Sul, 1990-2010. Cadernos EBAPE.BR, Rio de Janeiro, v. 9, n. 3, p. 914-945, 2011.

ALVES, D. P. Acesso à informação pública no Brasil: um estudo sobre a convergência e a harmonia existentes entre os principais instrumentos de transparência e de controle social. Distrito Federal: Controladoria-Geral da União, 2011. (Sexto Concurso de Monografias da CGU).

ALVES, A. S.; FERREIRA, S. B. L. Um mergulho nas recomendações de acessibilidade para conteúdo Web do W3C (WCAG2.0). 2011. Disponível em: http://www.seer.unirio.br/index.php/monografiasppgi/article/ view/1627/1439. Acesso em: 12 jan. 2019.

ATLAS SOCIOCONÔMICO DO RIO GRANDE DO SUL. Conselhos Regionais de Desenvolvimento - Coredes. 2015. Disponível em: http://www.atlassocioeconomico.rs.gov.br/upload/MAPAS_A4_Missoes.pdf. Acesso em: 26 nov. 2015.

ATLAS SOCIECONÔMICO DO RIO GRANDE DO SUL. Demografia. 2018. Disponível em: https://atlassocioeconomico.rs.gov.br/grau-de-urbanizacao. Acesso em: 14 jan. 2019.

BARBOSA, A. F. Governo eletrônico: dimensões da avaliação de desempenho na perspectiva do cidadão. 2008. Tese (Doutorado em Administração de Empresas) - Fundação Getúlio Vargas, Escola de Administração de Empresas, São Paulo, 2008.

BRASIL. Lei de Responsabilidade Fiscal. Lei Complementar no 101, de 04 de maio de 2000. 2000. Disponível em: http://www.planalto.gov.br/ccivil_03/leis/LCP/Lcp101.htm. Acesso em: 23 jul. 2016.

BRASIL. Lei da Transparência. Lei Complementar n 131, de 27 de maio de 2009. Presidência da República. Casa Civil. Subchefia para Assuntos Jurídicos. Brasília, 2009. Disponível em: http://www.planalto.gov. br/ccivil_03/leis/LCP/Lcp131.htm. Acesso em: 23 jul. 2016.

BRASIL. Lei de Acesso a Informações Públicas. Lei n 12.527, de 18 de novembro de 2011. Presidência da República. Casa Civil. Subchefia para Assuntos Jurídicos. Brasília, 2011. Disponível em: http://www.planalto.gov.br/ccivil_03/_ato2011-2014/2011/lei/I12527.htm. Acesso em: 23 jul. 2016.

CASTOLDI, G.; SANTOS, S. R. T. dos. A transparência na publicação eletrônica das informações municipais disponíveis em suas homepages: uma análise dos municípios pertencentes ao Corede Produção/RS. Revista Teoria e Evidência Econômica, Passo Fundo, v. 19, n. 40, p. 169-190, 2013.

COSTA, J. M. da; TORRES, F. J. V. Transparência pública: uma avaliação dos portais das prefeituras paraibanas sob a perspectiva do ITGP-M (2014). In: CONGRESSO UNB DE CONTABILIDADE E GOVERNANÇA, 1., 2015, Brasília. Anais [...]. Brasília: UnB, 2015. Disponível em: http://www.adcont.net/index.php/adcont/ adcont2015/paper/view/1773/442. Acesso em: 21 set. 2016.

COSTA J. M. da et al. O nível de transparência dos portais eletrônicos: o caso das capitais brasileiras. In: SEMINÁRIOS EM ADMINISTRAÇÃO, 19., 2016, São Paulo. Anais [...]. São Paulo: Semead, 2016. Disponível em: http://login.semead.com.br/19semead/anais/arquivos/1235.pdf. Acesso em: 2 set. 2017.

COSTA J. M. da. et al. A informação pública no Brasil: uma análise da transparência pública nos portais das prefeituras da Paraíba no ano de 2014. In: CONGRESSO NACIONAL DE ADMINISTRAÇÃO E CONTABILIDADE, 6., 2015, Rio de Janeiro. Anais [...]. Rio de Janeiro: AdCont, 2015. Disponível em: http://www.adcont. net/index.php/adcont/adcont2015/paper/viewFile/1773/442. Acesso em: 14 jan. 2019.

CRUZ, C. F. da. Transparência da gestão pública municipal: referenciais teóricos e a situação dos grandes municípios brasileiros. 2010. Dissertação (Mestrado em Ciências Contábeis) - Universidade Federal do Rio de Janeiro, Faculdade de Administração e Ciências Contábeis, Rio de Janeiro, 2010.

CRUZ, C. F. da et al. Transparência da gestão pública municipal: um estudo a partir dos portais eletrônicos dos maiores municípios brasileiros. Revista de Administração Pública, Rio de Janeiro, v. 46, n. 1, p. 153176, 2012.

CUCCINIELLO, M.; PORUMBESCU, G. A.; GRIMMELIKHUIJSEN, S. 25 years of transparency research: Evidence and future directions. Public Administration Review, v. 77, n. 1, p. 32-44, 2017.

DA SILVA ALVES, Aline; FERREIRA, Simone Bacellar Leal. Um Mergulho nas Recomendações de Acessibilidade para Conteúdo Web do W3C (WCAG2. 0). Disponível em: http://www.seer.unirio.br/index.php/monografiasppgi/article/view/1627/1439. Acesso em: 12 jan. 2019.

DINIZ, G. M. O estado da transparência digital de portais eletrônicos: um estudo nos municípios do Ceará. Revista do Tribunal de Contas do Estado de Minas Gerais, Belo Horizonte, v. 33, n. 4, p. 91-116, 2015.

FIRJAN. Índice Firjan de Desenvolvimento Municipal (IFDM). 2018. Disponível em: https://www.firjan. com.br/ifdm/. Acesso em: 14 jan. 2019.

GIACOMONI, J. Orçamento público. São Paulo, SP: Atlas, 2012. 
GOMES FILHO, Adhemar Bento. O desafio de implementar uma gestão pública transparente. In: CONGRESO INTERNACIONAL DEL CLAD SOBRE LA REFORMA DEL ESTADO Y DE LA ADMINISTRACIÓN PÚBLICA, 2005, Santiago, Chile. Anais [...]. Santiago, Chile. 2005.

JAMBEIRO, O.; SOBREIRA, R.; MACAMBIRA, L. Informação, participação cívica e controle da gestão pública: análise dos websites das capitais brasileiras. Revista de Economía Política de las Tecnologías de la Información y de la Comunicación, São Cristóvão, v. 14, n. 1, p. 1-28, 2012.

MEIJER, A. Understanding the complex dynamics of transparency. Public Administration Review, v. 73, n. 3, p. 429-439, 2013.

MPF. Ministério Público Federal. Ranking Nacional da Transparência. 2016. Disponível em: http://rankingdatransparencia.mpf.mp.br. Acesso em: 18 fev. 2019.

PAIVA, C. P. R.; ZUCCOLOTTO, R. Índice de transparência fiscal das contas públicas dos municípios obtidos em meios eletrônicos de acesso público. In: ENCONTRO NACIONAL DA ANPAD, 33., 2009, São Paulo. Anais [...]. São Paulo: Anpad, 2009.

PIRES, A. M. et al. Transparência da gestão pública municipal: um estudo dos municípios de Santa Maria e Novo Hamburgo/RS. Revista Estudos do Cepe, Santa Cruz do Sul, n. 38, p.131-160, 2013.

RAUPP, F. M.; PINHO, J. A. G. de. Portais eletrônicos de câmaras localizadas em pequenos municípios catarinenses: murais eletrônicos ou promotores de construção da prestação de contas, transparência e participação? Pensar Contábil, Rio de Janeiro, v. 14, n. 53, p. 35-44, 2012.

RAUPP, F. M.; PINHO, J. A. G. de. Accountability em câmaras municipais: uma investigação em portais eletrônicos. Revista de Administração, São Paulo, v. 48, n. 4, p.770-782, 2013.

RAUPP, F. M.; PINHO, J. A. G. de. Prestação de contas nos portais eletrônicos de Assembleias Legislativas: um estudo após a Lei de Acesso à Informação. Revista Gestão \& Planejamento, Salvador, v. 15, n. 1, p. 144-161, 2014.

RAUPP, F. M.; ZUCCOLOTTO, R. Investigando as publicações sobre transparência eletrônica em revistas nacionais. Revista do Cepe, Santa Cruz do Sul, v. 39, n. 67, p. 46-66, 2015.

ROCHA, A. C. Accountability na administração pública: a atuação dos tribunais de contas. In: ENCONTRO NACIONAL DA ANPAD, 33., 2009, São Paulo. Anais [...]. São Paulo: Anpad, 2009.

ROSSONI, F. V. Transparência na gestão pública municipal: uma análise nos sítios eletrônicos das prefeituras municipais do Estado do Espírito Santo. Vitória. 2013. Dissertação (Mestrado em Ciências Contábeis) Fundação Instituto Capixaba de Pesquisa em Contabilidade, Economia e Finanças (Fucape), Vitória, 2013. ROSSONI, F. V.; BEIRUTH, A. X. Transparência na gestão pública municipal: análise nos sites das prefeituras do Estado do Espírito Santo. Revista de Auditoria Governança e Contabilidade - RAGC, Monte Carmelo, v. 4, n. 17, p. 1-16, 2016.

SANTOS, P. M. et al. Ranking dos tribunais de contas brasileiros: uma avaliação a partir dos padrões web em governo eletrônico. Revista de Administração Pública, Rio de Janeiro, v. 47, n. 3, p. 721-744, 2013.

SANTOS, M. dos; VISENTINI, M. S. Elaboração de um ranking da transparência e compreensão das práticas de gestão de municípios integrantes do Corede Missões-RS. Administração Pública e Gestão Social, Viçosa, v. 10, n. 4, p. 239-247, 2018.

SELL, F. F. et al. Accountability: uma observação sobre o nível de transparência de municípios. Administração Pública e Gestão Social, Viçosa, v. 10, n. 4, p. 248-259, 2018.

SILVA, L. M. Contabilidade governamental: um enfoque administrativo. 8 ed. São Paulo: Atlas, 2009.

SOUZA, A. C. et al. A relevância da transparência na gestão pública municipal. Revista Campus, Paripiranga, v. 2, n. 5, p. 6-20, 2009. 